\title{
Diagnosis of Hirschsprung's disease by punch biopsy of rectum
}

\author{
P. W. B. PEASE, J. J. CORKERY, and A. H. CAMERON \\ From the Department of Paediatric Surgery and Pathology, Birmingham Children's Hospital
}

Pease, P. W. B., Corkery, J. J., and Cameron, A. H. (1976). Archives of Disease in Childhood, 51, 541. Diagnosis of Hirschsprung's disease by punch biopsy of rectum. 234 punch biopsy specimens of rectal tissue were taken from 112 children. In $94 \%$ of the patients the diagnosis of Hirschsprung's disease was confirmed or refuted by the first biopsy. There were no false-positive or false-negative results. One patient developed a serious complication, a pelvic haematoma.

In this paper we present evidence that punch biopsy of the rectum is a simple, safe, and reliable method of diagnosing Hirschsprung's disease.

\section{Patients and methods}

Between January 1970 and December 1974 a total of 234 punch biopsies of the rectum and colon were performed on 112 children. In 102 of the children the biopsy was to try to establish a diagnosis, whereas in the remaining 10 Hirschsprung's disease had already been diagnosed and serial biopsies were done to try to define the aganglionic segment. The age distribution of the children at the time of biopsy is shown in the Table.

TABLE

Age distribution of 112 children at time of biopsy

\begin{tabular}{l|c|c}
\hline \multicolumn{1}{c|}{ Age } & No. of patients & $\begin{array}{c}\text { Hirschsprung's } \\
\text { disease diagnosed }\end{array}$ \\
\hline$<1$ week & 19 & 5 \\
1-3 weeks & 18 & 7 \\
1-11 months & 38 & 15 \\
1-3 years & 24 & 5 \\
4-12 years & 13 & 3 \\
\hline Total & 112 & 35 \\
\hline
\end{tabular}

The technique used for taking rectal tissue samples was a modification of that described by Shandling (1961). Preparation of the bowel is unnecessary but suction through a $10 \mathrm{FG}$ catheter helps to clean any liquid meconium or faeces from the operative site. Preoperative vitamin $\mathrm{K}$ is essential in neonates. The

Received 27 October 1975 lithotomy position is most satisfactory in neonates while the left lateral position is more suitable in older children. A standard Chevalier-Jackson vocal cord biopsy forceps is used (Fig.). A view of the rectum is obtained in newborn infants by using a nasal speculum and in older patients by using a bivalve rectal speculum. A sigmoidoscope is used for serial biopsies higher up or via a colostomy.

With the forceps in position a bite of mucosa and submucosa enough to fill the cup is taken under direct vision. This action alone will not cut the specimen completely. While keeping the jaws firmly closed the instrument is sharply withdrawn. Specimens 3 to 5 $\mathrm{mm}$ in diameter are obtained in this way. Depending on the age of the patient, the samples for diagnostic biopsy are taken 2 to $3 \mathrm{~cm}$ above the dentate line to avoid the norma lhypoganglionic zone (Aldridge and Campbell, 1968). It is advisable to take two specimens from each patient in case one of them contains insufficient submucosa. After this procedure bleeding is minimal and ceases spontaneously.

Anaesthesia. Biopsy was performed under general anaesthesia in $47(42 \%)$ of the 112 patients. In 17 of the 47 the sample was taken at laparotomy or some other operative procedure for which the child was already

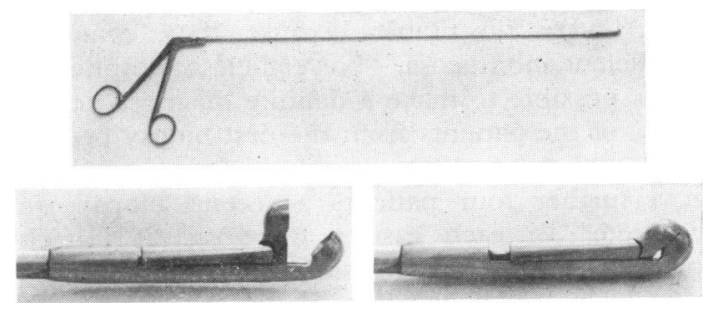

Fig.-Chevalier-Jackson biopsy forceps. 
anaesthetized. In 10 of the 47 serial biopsies entailing prolonged instrumentation were being performed. The remaining $20(18 \%$ of the total) were judged sufficiently 'uncooperative' to require general anaesthesia. In the 65 patients who were not anaesthetized the procedure was performed either in the ward or in the outpatient department.

Histological technique. The method followed was based on that described by Campbell and Noblett (1969) except that the specimens were not spread on Teflon gauze or other material before fixation. They were usually 4-5 $\mathrm{mm}$ in diameter and rounded or domeshaped, like the head of a young mushroom, and they were fixed in buffered $10 \%$ formalin and processed to paraffin. Usually a whitish core was recognizable corresponding to the stem of the mushroom. The specimen was embedded sideways so that sections would pass longitudinally through the core. The first few sections were discarded and the next 50 mounted in sets of 10. These were usually adequate for examination but if submucosa was not included a further 50 to 100 serial sections were made. The timing of the biopsy is of some importance in relation to the period of fixation and the total period for processing. Specimens received before noon were processed overnight and reported on within 24 hours. Those received later in the day were processed the following night and reported on within 48 hours. The specimen should be covered by colonic mucosa and the occasional one which showed squamous epithelium was not examined further, as this zone is normally aganglionic (Aldridge and Campbell, 1968). The submucosa of each section was examined under a $10 \times$ objective and points of detail were confirmed under higher power. Ganglion cells were considered absent if none were seen in $\mathbf{5 0}$ serial sections that included an adequate amount of submucosa. In addition, the diagnosis of Hirschsprung's disease was not accepted unless the aganglionic sections also showed thickened nerve trunks. In occasional specimens ganglion cells were not seen in 50 serial sections but the nerve trunks appeared to be of normal size. In these circumstances further sections were made and these always showed ganglion cells.

\section{Results}

The histology of 234 specimens from 112 patients was examined. Of the 234 specimens 25 $(11 \%)$ were unsuitable because they contained insufficient submucosa. Nevertheless, despite this it was possible to make a definite diagnosis in 105 $(94 \%)$ of the patients from the first biopsy because of the policy of taking two specimens from each. In a further four patients a second biopsy was required. In each case a diagnosis of Hirschsprung's disease was made. The remaining 3 patients in whom the first biopsy was inadequate were grossly mentally retarded. One failed to return for follow-up, and in the other 2 the probability of Hirschsprung's disease was so slight that a second biopsy was not considered justified.

Hirschsprung's disease was diagnosed in 35 ( $31 \%$ ) of the 112 patients. All the 35 subsequently had definitive pull-through operations for the disease. Resected material was examined histologically and the diagnosis of Hirschsprung's disease was confirmed in each case.

Complications. In 4 patients one or other of the two biopsy specimens included muscle as well as mucosa and submocosa. In 2 of these patients no untoward effects were seen. In the third bleeding from the biopsy site was unusually brisk and necessitated overnight observation in hospital, but blood transfusion was unnecessary. In the fourth patient a large pelvic haematoma developed resulting in urinary retention: this was due to a combination of the biopsy procedure coinciding with the onset of haemorrhagic disease of the newborn and preoperative vitamin $\mathrm{K}$ having been accidentally omitted.

\section{Discussion}

Normally ganglion cells are present in both the submucous and myenteric plexuses throughout the length of the bowel wall. At the anal end there is a hypoganglionic zone where ganglion cells may normally be scanty or absent (Bodian, Stephens, and Ward, 1949). In the myenteric plexus this zone extends proximally from the anal valves for, on average, a distance of $4 \mathrm{~mm}(0-14 \mathrm{~mm})$. In the submucous plexus the corresponding distance is $10 \mathrm{~mm}$ (3-17 mm) (Aldridge and Campbell, 1968). In Hirschsprung's disease ganglion cells are absent from both plexuses in the affected segment of bowel.

Full thickness biopsy of the rectum, as described by Swenson, Fisher, and MacMahon (1965), is a technically difficult procedure and not without hazards, especially in neonates. General anaesthesia is always necessary. Bodian (1960) showed that full thickness biopsy was not necessary for the diagnosis of Hirschsprung's disease and that histological examination of the submucosal plexus only was sufficient. He recommended taking a specimen of mucosa and submosa $0.5 \mathrm{~cm} \times 2 \mathrm{~cm}$. Several papers since have shown that much smaller biopsy specimens are perfectly adequate (Shandling, 1961 ; Dobbins and Bill, 1965; Campbell and Noblett, 1969) and Noblett (1969) devised a special suction instrument for obtaining specimens of the rectal mucosa.

A word of caution about the histological assess- 
ment in these biopsies is necessary. There is no doubt that pathologists who are asked only occasionally to examine such material find assessment very difficult and misleading. The ganglion cells may not be recognized. They may easily be confused with endothelial cells of obliquely cut blood vessels without a lumen, and also with isolated muscle cells which commonly lie detached below the muscularis mucosae. Special stains are of little help and only regular experience can ensure reliable results.

Our experience further confirms that, so long as the biopsy specimen is taken at the correct level and the histological technique we have described is adhered, to, punch biopsy of the rectal mucosa and submucosa is reliable in confirming or refuting the diagnosis of Hirschsprung's disease. A tissue sample can be safely obtained at any age without bowel preparation and usually without general anaesthesia. Furthermore, a readily available, comparatively cheap, unmodified, Chevalier-Jackson biopsy forceps is especially suitable for the purpose. The specimens taken by this method are quite suitable for the assessment of acetylcholinesterase activity in cryostat sections, as described by Meier-Ruge et al. (1972). For a while we followed this method in parallel with the paraffin procedure, but on occasions we found it to be unreliable. It is doubtful whether the shorter processing time, about 2 hours, is of much practical advantage and it is no longer used.

We believe that full thickness rectal biopsy is no longer necessary or justified in the diagnosis of Hirschsprung's disease.

\section{REFERENCES}

Aldridge, A. T., and Campbell, P. E. (1968). Ganglion cell distribution in the normal rectum and anal canai. Fournal of Pediatric Surgery, 3, 475.

Bodian, M. (1960). Recent Advances in Clinical Pathology, 3rd series, p. 384. Ed. by S. C. Dyke. Churchill, London.

Bodian, M., Stephens, F. D., and Ward, B. C. H. (1949). Hirschsprung's disease and idiopathic megacolon. Lancet, 1, 6 .

Campbell, P. E., and Noblett, H. R. (1969). Experience with rectal suction biopsy in the diagnosis of Hirschsprung's disease. Journal of Pediatric Surgery, 4, 410.

Dobbins, W. O., and Bill, A. H., Jr. (1965). Diagnosis of Hirschsprung's disease excluded by rectal suction biopsy. New England fournal of Medicine, 272, 990.

Meier-Ruge, W., Lutterbeck, P. M., Herzog, B., Morger, R., Moser, R., and Schärli, A. (1972). Acetylcholinesterase activity in suction biopsies of the rectum in the diagnosis of Hirschsprung's disease. Fournal of Pediatric Surgery, 7, 11.

Noblett, H. R. (1969). Rectal suction biopsy tube for use in the diagnosis of Hirschsprung's disease. Fournal of Pediatric Surgery, 4, 406.

Shandling, B. (1961). A new technique in the diagnosis of Hirschsprung's disease. Canadian fournal of Surgery, 4, 298.

Swenson, O., Fisher, J. H., and MacMahon, H. E. (1955). Rectal biopsy as an aid in the diagnosis of Hirschsprung's disease. New England fournal of Medicine, 253, 632.

Correspondence to Mr. J. J. Corkery, The Children's Hospital, Ladywood Middleway, Ladywood, Birmingham B16 8ET. 